\title{
Ghrelin Concentrations Reflect Body Mass Index Rather Than Feeding Status in Obese Girls
}

\author{
CAROL M. FOSTER, ARIEL BARKAN, JOSEPHINE Z. KASA-VUBU, AND CRAIG JAFFE
}

\author{
Department of Pediatrics/Endocrinology [C.M.F.], University of Utah, Salt Lake City, Utah 84108; Department of Internal \\ Medicine/Endocrinology and Metabolism [A.B., C.J.], Department of Pediatrics/Endocrinology [J.Z.K.-V.], University of Michigan, \\ Ann Arbor, Michigan 48109
}

\begin{abstract}
Ghrelin stimulates both appetite and secretion of growth hormone $(\mathrm{GH})$. We hypothesized that fasting should increase ghrelin, thereby increasing GH concentrations in obesity. Eight obese girls underwent a 48 -h fast, receiving $25 \%$ of calories for ideal body weight. Blood was obtained every $15 \mathrm{~min}$ for the last $24 \mathrm{~h}$ of the fast. Four months later, six obese girls had blood obtained in the fed state. Two additional obese and five lean girls had blood obtained in the fed state. Ghrelin was determined in 3-h pools. Mean ghrelin concentrations were $0.41 \pm 0.03 \mathrm{ng} / \mathrm{mL}$ for lean girls and $0.16 \pm 0.01 \mathrm{ng} / \mathrm{mL}$ in obese fed girls $(p<0.0001)$. Lean fed girls had diurnal variation of ghrelin whereas obese fed girls did not. Fasting neither increased ghrelin $(0.18 \pm 0.01 \mathrm{ng} / \mathrm{mL})$ nor restored diurnal variation. Ghrelin concentrations were related to the body mass index (BMI) SD score (SDS) $(r=0.45, p=0.005)$. For the six obese girls who participated in both fasting and fed studies, change in mean ghrelin concentration between studies was related to change in BMI SDS but not fed or fasting state. Ghrelin concentrations are, thus, a function of BMI rather than feeding status in obese girls. (Pediatr Res 62: 731-734, 2007)
\end{abstract}

$\mathrm{G}^{\mathrm{n}}$ hrelin is the natural ligand for the growth hormone $(\mathrm{GH})$ secretagogue receptor and is a potent stimulus for pituitary GH release in humans (1). Ghrelin is also an orexigenic peptide, producing hunger when given exogenously $(2,3)$. Ghrelin concentrations vary diurnally, increasing during sleep at night when food intake is absent. Ghrelin also increases before meals and decreases after feeding supporting its role in appetite regulation $(4,5)$. Like ghrelin, serum GH concentrations exhibit diurnal variation such that the amplitude of secretory bursts is greater at night than during the waking hours (6). GH concentrations increase significantly in both children and adults during fasting $(7,8)$. Ghrelin and $\mathrm{GH}$ concentrations vary inversely with body mass index as a reflection of central adiposity, and both are lower in obese individuals (9-11). The fact that ghrelin is both a stimulus for GH release and a mediator of energy homeostasis suggests that ghrelin might promote the increase of $\mathrm{GH}$ secretion during fasting. In adults, however, the lack of a consistent

Received March 21, 2007; accepted July 22, 2007.

Correspondence: Carol M. Foster, M.D., Department of Pediatrics/Endocrinology, University of Utah, 615 Arapeen Dr., Suite 100, Salt Lake City, UT 84108; e-mail: carol.m.foster@hsc.utah.edu

This study was supported by a grant from the Genentech Foundation for Clinical Research and by the General Clinical Research Center of the University of Michigan (RR-00045) and K23 DK065995 (JKV).

Presented in part at the 2006 Annual Meeting of the Western American Federation for Medical Research. increase in ghrelin concentrations with short-term fasting has cast doubt on the role of ghrelin as a nutritional regulator of GH secretion $(12,13)$.

Although ghrelin is unlikely to play a significant role in maintenance of adult GH concentrations, a separate study of the role of ghrelin in children is important, since $\mathrm{GH}$ physiology is significantly different between adults and growing children. A notable example of the difference is that children have higher spontaneous GH concentrations than do adults in the face of greater IGF-1 concentrations than present in adults (14). Thus, in this study, we have compared ghrelin diurnal concentrations in obese and lean girls and have examined the relationship between ghrelin concentrations and fasting in obese girls. We hypothesized that fasting in obese girls would increase ghrelin concentrations by the same extent as the fasting-induced increase in $\mathrm{GH}$ concentration we have demonstrated previously in obese girls.

\section{METHODS}

Subjects. The clinical characteristics of the 15 girls studied are shown in Table 1. Eight of the obese girls took part in a fasting study and six were restudied in the fed state 4 mo later. Two obese girls had frequent blood sampling because they had a history of precocious thelarche and chose to have detailed assessment of gonadotropin secretion. Neither of these girls had central precocious puberty. The five lean girls were studied for delayed adolescence and/or short stature. None had GH deficiency and all have now progressed normally through puberty and have had onset of menses. GH results have been presented in part previously during fasting for subjects 1 through 8 and during the fed state for subjects 11 through 15 (7).

Protocol. Protocols were approved by the Institutional Review Board of the University of Michigan, and studies were conducted in the University of Michigan General Clinical Research Center (GCRC). Written informed consent was obtained from a parent and written or verbal consent from each girl before study. The girls were all admitted at $1700 \mathrm{~h}$ on the night before study to allow acclimatization to the GCRC. Meals were provided on the GCRC schedule at 0700, 1130, and $1700 \mathrm{~h}$. Snacks were provided at 0930, 1400, and $2100 \mathrm{~h}$. Girls stayed in their rooms with limited physical activity. Lights were turned off at $2200 \mathrm{~h}$ and on at $0600 \mathrm{~h}$.

Lean girls and obese girls with only fed studies. Girls slept one night in the General Clinical Research Center to acclimate to the research setting. An i.v. catheter was placed in a forearm vein at $0600 \mathrm{~h}$. Blood was obtained every $15 \mathrm{~min}$ for $24 \mathrm{~h}$ beginning at $0800 \mathrm{~h}$.

48-h Fasting studies. The GCRC dietitian calculated each girl's caloric needs based on ideal body weight and then provided a balanced diet consisting of $25 \%$ of her estimated caloric needs in three meals and snacks on the GCRC meal schedule. Noncaloric beverages were provided ad libitum. Fasting began at $0800 \mathrm{~h}$. On the second fast day, an i.v. catheter was placed in a forearm vein at $0600 \mathrm{~h}$ and blood was obtained every $15 \mathrm{~min}$ for the

Abbreviations: GCRC, General Clinical Research Center; GHRH, growth hormone-releasing hormone 
Table 1. Clinical characteristics

\begin{tabular}{|c|c|c|c|c|}
\hline Subject no. & Study type & Age (y) & BMI SDS* (fast/fed) & Pubertal stage ${ }^{* *}$ \\
\hline \multicolumn{5}{|l|}{ Obese } \\
\hline 1 & Fast/fed & 7.3 & $5.4 / 6.0$ & I \\
\hline 2 & Fast/fed & 8.6 & $10.4 / 10.6$ & I \\
\hline 4 & Fast/fed & 9.6 & $4.2 / 3.8$ & I \\
\hline 5 & Fast/fed & 9.8 & $10.0 / 9.0$ & III \\
\hline 6 & Fast/fed & 11.2 & $7.2 / 6.8$ & II \\
\hline 9 & Fed & 6.0 & 4.0 & II \\
\hline 10 & Fed & 8.3 & 4.6 & II \\
\hline Mean $\pm \mathrm{SE}$ & Fast & $9.3 \pm 0.5$ & $8.2 \pm 0.8$ & \\
\hline Mean \pm SE & Fed & $8.9 \pm 0.6^{\dagger}$ & $6.9 \pm 1.0$ & \\
\hline \multicolumn{5}{|l|}{ Lean } \\
\hline 11 & Fed & 9.9 & -1.2 & I \\
\hline Mean $\pm \mathrm{SE}$ & Fed & $12.8 \pm 0.8$ & $-1.2 \pm 0.2$ & \\
\hline
\end{tabular}

* Body Mass Index Standard Deviation Score determined as adapted by Susan R. Rose, 2000 from NCHS and the National Center for Chronic Disease Prevention and Health Promotion (2000).

** Pubertal stage determined by the method of Tanner. Stage for breast and pubic hair averaged and rounded up.

$\dagger$ Age adjusted to account for 4 mo between fast and fed studies for subjects 1 to 5 .

remaining $24 \mathrm{~h}$ of the fast. Thus, blood was sampled frequently for $24 \mathrm{~h}$ in the second day of a 48-h fast. Following the fast, girls were given dietary instruction regarding weight loss and seen in the GCRC as outpatients monthly for 3 mo for follow-up instruction. Six girls were readmitted at month 4 and had a study as described for the lean girls, above.

Hormone assays. Blood samples were obtained in heparinized tubes and kept at $4^{\circ} \mathrm{C}$ until, within $24 \mathrm{~h}$, an aliquot of each blood sample from 3-h periods throughout the 24-h time of sampling was pooled, making eight samples comprising the times: $0800-1045,1100-1345,1400-1645,1700-$ $1945,2000-2245,2300-0145,0200-0445$, and $0500-0800 \mathrm{~h}$. The aliquot time blocks were used to allow reproductive hormone assay for an additional study. These samples were frozen at $-70^{\circ} \mathrm{C}$ and thawed twice before the thaw for the ghrelin assay. Total ghrelin was determined by RIA using an ELISA sandwich assay as previously described (13). The assay sensitivity was 30 $\mathrm{pg} / \mathrm{mL}$. All samples were assayed in a single assay. The intraassay variability was $<10 \%$.

GH was determined by chemiluminescent assay using reagents from Nichols (San Juan Capistrano, CA). The assay sensitivity was $0.01 \mathrm{ng} / \mathrm{mL}$ and the mean coefficient of variation was $6.5 \%$. Five girls, all obese fed subjects, had samples run in a DPC Immulite chemiluminescent assay at a later date. Twenty-four samples run in the Nichols chemiluminescent assay were also run in the DPC Immulite chemiluminescent assay for comparison. This assay had a coefficient of variation of $2 \%$ and samples in direct comparison were 1.38 -fold greater than in the Nichols assay. The GH values for these five girls were reduced by a factor of 1.38 and included in the analyses.

Statistical analyses. Ghrelin concentrations were log-transformed before analysis to decrease data heterogeneity. Analyses across time were performed by repeated measures ANOVA and across treatments by factorial ANOVA followed by Scheffé test. For time studies, the data for subject 1 was excluded because of missing values. Comparison of percentage change between treatments was assessed by simple regression. A $p$ value of $<0.05$ was considered significant.

\section{RESULTS}

Diurnal ghrelin concentrations. Ghrelin concentrations across time are shown in Figure 1. The lean subjects had significant variation of ghrelin concentrations by time block $(p=$ $0.019)$ that was not seen in obese girls during either the fed or fasted state $(p=0.3)$. In the lean girls, ghrelin concentrations were high in the 0800-1045 h time block, declined during the day, increased in the afternoon, and declined after the evening meal to then increase during sleep. Mean ghrelin concentrations were greater in the lean girls than in the obese fed girls $(0.41 \pm$ 0.03 versus $0.16 \pm 0.01 \mathrm{ng} / \mathrm{mL}, p<0.0001$ ) or in the obese girls in the fasted state $(0.18 \pm 0.01 \mathrm{ng} / \mathrm{mL}, p<0.0001)$. Ghrelin concentrations did not increase with increased time of fasting in the obese girls.

Ghrelin comparison to GH concentrations. Mean 24-h GH concentrations were $1.95 \pm 0.37 \mathrm{ng} / \mathrm{mL}$ for the lean girls, $0.89 \pm$ $0.13 \mathrm{ng} / \mathrm{mL}$ for the fed obese girls and $0.90 \pm 0.11 \mathrm{ng} / \mathrm{mL}$ for the fasted obese girls (Fig. 1). GH concentrations were significantly greater in the lean girls than in the fed obese girls $(p=0.03)$ but not different compared with the fasted obese girls $(p=0.17)$. The area under the $\mathrm{GH}$ curve was $13 \%$ greater for the fasted obese girls than the fed obese girls. Both obese fasted and fed girls and lean girls had an increase in GH at night with maximal concentrations achieved in the 2300-0145-h time block. No relationship existed between ghrelin and GH concentrations when all girls' data were analyzed. There were no significant changes in $\mathrm{GH}$ and ghrelin concentrations in the six girls who participated in the fed and fasting studies.

Ghrelin, body mass index (BMI) SD score, and feeding status. Mean ghrelin concentrations demonstrated a significant inverse correlation with body mass index SDS (standard deviation score) $\left(r^{2}=0.45, p=0.005\right)$ for lean and obese children in the fed state (Fig. 2). Mean ghrelin and GH concentrations for the six obese girls who were examined in the fed and fasting states are shown in Table 2. Fasting failed to increase ghrelin concentrations in these obese girls. Four of these six girls had a decline in BMI SD score whereas two gained weight in the 4 mo between studies. The change in ghrelin concentrations between fed and fasting studies was inversely related to the change in BMI SD score $\left(r^{2}=0.64 ; p\right.$ $=0.05$ ). 


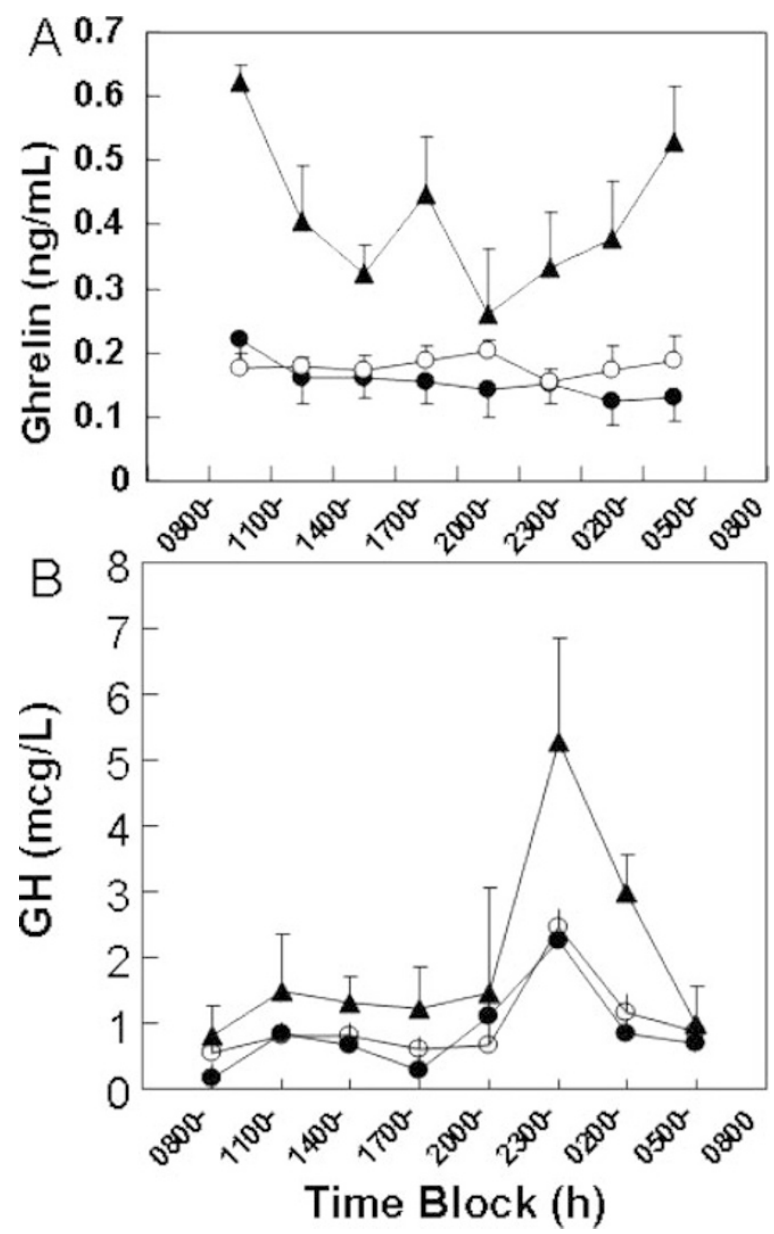

Figure 1. Twenty-four-hour concentrations of ghrelin $(A)$ and GH $(B)$. Five lean girls $(\mathbf{\Delta})$ and 7 obese girls $(\circlearrowleft)$ had blood obtained every $15 \mathrm{~min}$ for $24 \mathrm{~h}$ during spontaneous consumption of three meals and two snacks. An equal aliquot of serum from each sample in the designated 3-h time blocks was assayed for ghrelin and GH. Five of the fed-study obese girls and two additional obese girls $(O)$ underwent a modified 48 -h fast. Blood was obtained every 15 min during the last $24 \mathrm{~h}$ of fasting. Lean girls had diurnal variability and significantly greater ghrelin and GH concentrations compared with fed obese girls. Fasting ghrelin concentrations were greater than in the fed-state for obese girls. Data for subject 1 was excluded because of missing values.

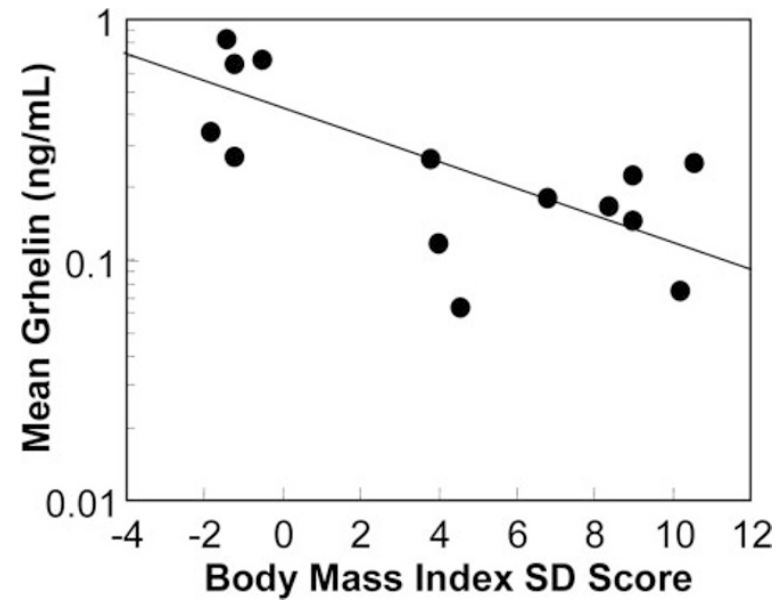

Figure 2. Relationship between ghrelin and BMI. Regression was performed between the mean 24-h ghrelin concentration and BMI in five lean and nine obese girls $(r=0.663)$. Data were taken from the fed study for the girls who had both a fed and fasted study. Data from subject 1 was excluded due to missing values.
Table 2.

Relationship between ghrelin, GH, and BMI in obese girls during fed and fasted studies $(n=6)$

\begin{tabular}{lccc}
\hline & Fed & Fasted & $\begin{array}{c}\text { Relationship to } \\
\text { change in BM } \\
\text { SD Score }\left(r^{2}, p\right)\end{array}$ \\
\hline Ghrelin $(\mathrm{ng} / \mathrm{mL})$ & $0.33 \pm 0.15$ & $0.27 \pm 0.10$ & $0.64,0.05$ \\
GH & $0.79 \pm 0.14$ & $0.92 \pm 0.20$ & $0.28,0.35$ \\
\hline
\end{tabular}

\section{DISCUSSION}

Ghrelin profiles in lean children are similar to those reported in adults $(4,5)$. Ghrelin concentrations in lean girls exhibit a diurnal variability with increases before breakfast and dinner, decreases after breakfast and dinner, and increases during the period of fasting at night. Lunchtime changes may have been masked by our decision to pool samples from 1100 to $1400 \mathrm{~h}$. As has been reported in adults and in single blood sample analysis in children, mean 24-h ghrelin concentrations are related to body mass index, which is a measure of adiposity $(9-11)$. Unlike reports for adults and in contrast to lean girls, ghrelin concentrations in obese girls have no diurnal variation and fail to increase even with a prolonged period of calorie restriction. In cross-sectional analysis, ghrelin concentrations during calorie restriction are greater than without calorie restriction. Analysis of individual samples, as opposed to pooled aliquots, might reveal diurnal variability, but this was not possible due to limited sample volume. However, comparison of fed and fasting ghrelin concentrations in the same child indicates that ghrelin is less a function of food intake in obese children than of BMI.

Ghrelin concentrations decrease with pubertal maturation (15). The relationship between BMI and ghrelin could be confounded by the decline in ghrelin with puberty combined with an increase in BMI as puberty advances. We tried to minimize the pubertal effect of increasing BMI by performing our analyses using BMI-SDS. In addition, although the girls in this study were peripubertal, and the study was conducted over $3 \mathrm{mo}$, it is unlikely that the changes in ghrelin concentration were related to advancing pubertal maturation. First, the girls had no discernible change in sexual maturation during the study. Second, ghrelin concentrations did not decline significantly between the first and second study. However, the study results may have been affected by the length of time between studies.

Studies in obese adults have shown variable ghrelin responses to fasting. In a study by Cummings et al. (16), obese adults appear to have diurnal variation in ghrelin concentrations and change in ghrelin with fasting. A study by Avram et al. (13), however demonstrated an absence of variability of ghrelin and no change in ghrelin concentrations with fasting, similar to what we observed in our obese girls. The discrepancy in results between our studies and those of others may be related to the degree of obesity in the subjects studied. Our subjects had an average BMI more than 8 SD above the mean for age and therefore were significantly overweight. In obese adults, long-term diet restriction that results in weight loss is associated in an increase in ghrelin concentrations (16). Even 
in healthy lean adults, there is a lack of consistency in the effects of acute fasting on ghrelin concentrations $(12,13)$. Thus, mean ghrelin concentrations in both adults and children appear to be controlled principally by adiposity.

GH secretion is attenuated in obesity whether in children or adults $(6,7)$. When ghrelin or ghrelin-like peptides are given exogenously, they release GH through a complex mechanism that may involve the up-regulation of hypothalamic GHreleasing hormone $(17,18)$. In our obese girls, fasting was associated with an approximate 15\% increase in both ghrelin and $\mathrm{GH}$. Our obese girls had a nocturnal increase in GH concentration that was not associated with an increase in ghrelin. This argues against an acute role of ghrelin in the control of GH secretion in children as well as in adults. Recently, it has been shown that direct ghrelin administration to rodent hypothalami does not produce an acute increase in either growth hormone-releasing hormone (GHRH) or GH secretion (18). However, rodents with transgenic antisense blockade of the GH secretagogue (GHS) receptor, the ghrelin receptor, have lower production of GHRH while mice with transgenic expression of the GHS receptor have higher production of GHRH compared with wild-type animals (18-20). Thus, whereas ghrelin probably does not acutely regulate GH secretion, it likely contributes to the overall hypothalamic content of GHRH thereby influencing GH concentrations. Like ghrelin concentrations, GH concentrations are inversely correlated to BMI when serving as a marker of adiposity (21). However, direct links between ghrelin and GH have not been ascertained when studied rigorously in adults (13). Whether and how ghrelin participates in regulating GH concentrations in humans remains to be determined. The increase in GH seen with fasting is thought to be related to the decrease in insulin concentration, which decreases hepatic IGF-1 production. The decline in IGF-1 then serves to increase GH concentrations via a feedback relationship $(22,23)$.

These studies demonstrate that lean girls have diurnal variability of ghrelin secretion, similar to what has been demonstrated in adults. Also, in girls, mean 24-h concentrations of ghrelin correlate significantly with BMI, as in adults. Morbid obesity in girls results in the loss of diurnal variation of ghrelin concentrations. As weight decreases in girls, ghrelin concentrations increase whereas with weight gain, ghrelin concentrations decrease. Although changes in ghrelin cannot explain the nocturnal increase in GH secretion, ghrelin still may participate in regulating the hypothalamic content of GHRH and thus indirectly influence $\mathrm{GH}$ concentrations.

\section{REFERENCES}

1. Kojima M, Hosoda H, Date Y, Nakazato M, Matsuo H, Kangawa K 1999 Ghrelin is a growth-hormone-releasing acylated peptide from stomach. Nature 402:656-660
2. Nakazato M, Murakami N, Date Y, Kogima M, Matsuo H, Kangawa K, Matsukura S 2001 A role for ghrelin in the central regulation of feeding. Nature 409:194-198

3. Wren AM, Seal LJ, Cohen MA, Brynes AE, Frost GS, Murphy KG, Dhillo WS, Ghatei MA, Bloom SR 2001 Ghrelin enhances appetite and increases food intake in humans. J Clin Endocrinol Metab 86:5992-5995

4. Cummings DE, Purnell JQ, Frayo RS, Schmidova K, Wisse BE, Weigle DS 2001 A preprandial rise in plasma ghrelin levels suggests a role in meal initiation in humans. Diabetes 50:1714-1719

5. Cummings DE, Frayo RS, Marmonier C, Aubert R, Chapelot D 2004 Plasma ghrelin levels and hunger scores in humans initiating meals voluntarily without time- and food-related cues. Am J Physiol Endocrinol Metab 287:E297-E304

6. Jaffe CA, Ocampo-Lim B, Buo W, Krueger K, Sugahara I, DeMott-Friberg R, Bermann M, Barkan AL 1998 Regulatory mechanisms of growth hormone secretion are sexually dimorphic. J Clin Invest 102:153-164

7. Kasa-Vubu JZ, Barkan A, Olton P, Meckmongkol T, Carlson NE, Foster CM 2002 Incomplete modified fast in obese early pubertal girls leads to an increase in 24-hour growth hormone concentrations and a lessening of the circadian patter in leptin. J Clin Endocrinol Metab 87:1885-1893

8. Hartman ML, Pezzoli SS, Hellmann PJ, Suratt PM, Thorner MO 1996 Pulsatile growth hormone secretion in older persons is enhanced by fasting without relationship to sleep stages. J Clin Endocrinol Metab 81:2694-2701

9. Tschop M, Weyer C, Tatranni PA, Devanarayan V, Ravussin E, Heiman ML 2001 Circulating ghrelin levels are decreased in human obesity. Diabetes 50:707-709

10. Ha AM, Farooqi IS, O'Rahilly S, Stadler DD, Rosenfeld RG, Pratt KL, LaFranchi SH, Purnell JQ 2003 Serum ghrelin levels are inversely correlated with body mass index, age, and insulin concentrations in normal children and are markedly increased in Prader-Willi syndrome. J Clin Endocrinol Metab 88:174-178

11. Vahl N, Jorgensen JO, Skjaerback C, Veldhuis JD, Orskov H, Christiansen J 1997 Abdominal adiposity rather than age and sex predicts the mass and patterned regularity of growth hormone secretion in mid-life healthy adults. Am J Physiol 272:E1108-E1116

12. Doucet E, Pomerleau M, Harper ME 2004 Fasting and postprandial total ghrelin remain unchanged after short-term energy restriction. J Clin Endocrinol Metab 89:1727-1732

13. Avram AM, Jaffe CA, Symons KV, Barkan AL 2005 Endogenous circulating ghrelin does not mediate GH rhythmicity or response to fasting. J Clin Endocrinol Metab 90:2982-2987

14. Ghigo E, Arvat E, Gianotti L, Lanfranco F, Broglio F, Aimaretti G, Maccario M, Camanni F 2000 Hypothalamic growth hormone-insulin-like growth factor-I axis across the human life span. J Pediatr Endocrinol Metab 13:1493-1502

15. Chanoine JP 2005 Ghrelin in growth and development. Horm Res 63:129-138

16. Cummings DE, Weigle DS, Frayo RS, Breen PA, Ma MK, Dellinger EP, Burnell JQ 2002 Plasma ghrelin levels after diet-induced weight loss or gastric bypass surgery. N Engl J Med 346:1623-1630

17. Howard AD, Feighner SD, Cully DF, Arena JP, Liberator PA, Rosenblum CI, Hamelin M, Hreniuk DL, Palyha OC, Anderson J, Paress PS, Diaz C, Chou M, Liu KK, McKee KK, Pong S-S, Chaung L-Y, Elbrecht A, Dashkevicz M, Heavens R, Rigby M, Sirinathsinghii DJ, Dean DC, Melillo DG, Patchett AA, Nargund R, Griffin PR, DeMartino JA, Gupta SK, Schaeffer JM, Smith RG, Van der Ploeg LH 1996 A receptor in pituitary and hypothalamus that functions in growth hormone release. Science 273:974-977

18. Mano-Otagiri A, Nemoto T, Sekino A, Yamauchi N, Shuto Y, Sugihara H, Oikawa S, Shibasaki T 2006 Growth hormone-releasing hormone (GHRH) neurons in the arcuate nucleus (Arc) of the hypothalamus are decreased in transgenic rats whose expression of ghrelin receptor is attenuated: evidence that ghrelin receptor is involved in the up-regulation of GHRH expression in the Arc. Endocrinology 147:4093-4103

19. Shuto Y, Shibasaki T, Otagiri A, Kuriyama H, Ohata H, Tamura H, Kamegai J, Sugihara H, Oikawa S, Wakabayashi I 2002 Hypothalamic growth hormone secretagogue receptor regulates growth hormone secretion, feeding, and adiposity. J Clin Invest 109:1429-1436

20. Lall S, Balthasar N, Carmignac D, Magoulas C, Sesay A, Houston P, Mathers K, Robinson I 2004 Physiological studies of transgenic mice overexpressing growth hormone $(\mathrm{GH})$ secretagogue receptor $1 \mathrm{~A}$ in GH-releasing hormone neurons. Endocrinology 145:1602-1611

21. Iranmanesh A, Lizarralde G, Veldhuis JD 1991 Age and relative adiposity are specific negative determinants of the frequency and amplitude of growth hormone (GH) secretory bursts and the half-life of endogenous GH in healthy men. J Clin Endocrinol Metab 73:1081-1088

22. Brismar K, Fernqvist-Forbes F, Wahren J, Hall K 1994 Effect of insulin on the hepatic production of insulin-like growth factor-binding protein-1 (IGFBP-1), IGFBP-3, and IGF-I in insulin-dependent diabetes. J Clin Endocrinol Metab 79:872878

23. Ghigo E, Gianotti L, Arvat E, Ramunni J, Valetto MR, Broglio F, Rolla M, Cavagnini F, Müller EE 1999 Effects of recombinant human insulin-like growth factor I administration on growth hormone $(\mathrm{GH})$ secretion, both spontaneous and stimulated by GH-releasing hormone or hexarelin, a peptidyl GH secretagogue, in humans. J Clin Endocrinol Metab 84:285-290 